University of Nebraska - Lincoln

DigitalCommons@University of Nebraska - Lincoln

2008

\title{
Memory in Food Caching Animals
}

\author{
Alan C. Kamil \\ University of Nebraska - Lincoln, akamil1@unl.edu \\ Kristy L. Gould \\ Luther College, Decorah, IA, goulkr01@luther.edu
}

Follow this and additional works at: https://digitalcommons.unl.edu/bioscibehavior

Part of the Behavior and Ethology Commons

Kamil, Alan C. and Gould, Kristy L., "Memory in Food Caching Animals" (2008). Papers in Behavior and Biological Sciences. 61.

https://digitalcommons.unl.edu/bioscibehavior/61

This Article is brought to you for free and open access by the Papers in the Biological Sciences at DigitalCommons@University of Nebraska - Lincoln. It has been accepted for inclusion in Papers in Behavior and Biological Sciences by an authorized administrator of DigitalCommons@University of Nebraska - Lincoln. 
Published (as Chapter 22) in Learning and Memory:A Comprehensive Reference, Volume I Learning Theory and Behaviour, edited by Randolf Menzel, John H. Byrne, Editor-in-Chief (Amsterdam: Elsevier, 2008), pp. 4I9-439. Copyright (C) 2008 Elsevier Ltd. Used by permission.

\title{
Memory in Food Caching Animals
}

\author{
A. C. Kamil, University of Nebraska-Lincoln, Lincoln, NE, USA
}

K. L. Gould, Luther College, Decorah, IA, USA

$\begin{array}{lll}\text { I Introduction } & 419\end{array}$

2 The Natural History of Food Storage $\quad 420$

3 Establishing the Role of Memory 42I

3.I Experimental Evidence for Spatial Memory 42I

3.2 The Characteristics of Cache Memory and Retrieval 422

3.2.1 Memory duration $\quad 422$

3.2.2 Memory for cache contents 423

$\begin{array}{lll}3.2 .3 & \text { Order of recovery } & 423\end{array}$

$\begin{array}{lll}3.2 .4 & \text { Proactive and retroactive interference } & 423\end{array}$

$\begin{array}{lll}3.2 .5 & \text { Dynamism of memory } & 424\end{array}$

$\begin{array}{lll}\text { 3.2.6 } & \text { Are all caches created equal? } & 424\end{array}$

3.3 Coding of Cache Site Locations 424

3.3.1 Landmark use during the recovery of stored food 425

3.3.2 Landmarks and the coding of spatial locations 426

$4 \quad$ The Evolution of Spatial Memory in Seed-Caching Animals 428

4.I Cache-Site Memory 428

$\begin{array}{lll}4.2 & \text { Noncache-Site Memory } & 429\end{array}$

4.2.1 Window shopping 429

$\begin{array}{lll}4.2 .2 & \text { One-trial associative tasks } & 429\end{array}$

4.2.3 Open-room radial maze 430

4.2.4 Operant tasks 43I

$5 \quad$ Neural Substrates $\quad 432$

5.I $\quad$ Role of the Hippocampus in Spatial Memory 432

5.2 The Hippocampus in Food-Storing Birds 432

5.3 Experience, Seasonality, and Neurogenesis in Birds 433

$5.4 \quad$ Role of the Hippocampus in Mammals 434

$\begin{array}{lll}5.5 & \text { Other Brain Areas } & 435\end{array}$

$\begin{array}{lll}5.6 & \text { Cognitive Pleiotropy } & 435\end{array}$

$6 \quad$ Conclusions $\quad 436$

References $\quad 436$

\section{Introduction}

One of the more interesting developments in the study of learning and cognition over the past 25 years has been the realization that learning and memory play an important role in the natural world of many animals (e.g., Balda et al., 1998). As this realization led to research into animal cognition in natural settings, it became clear that such research can make important contributions to our understanding of animal and human cognition. In this chapter, we review one of the areas of research that originally stimulated interest in the role of memory in the field, the ability of many food-storing animals to remember where they have cached their food (See also Chapter 23 in Learning and Memory: A Comprehensive Reference, Volume I (2008), ed. R. Menzel).

We will begin our review of research in this area with a brief review of the natural history and ecological significance of food-caching. We will then review the evidence demonstrating the use of memory for accurate cache recovery, followed by a discussion of the charac- 
teristics of cache site memory and the comparative evidence for differences in memory among caching and noncaching species. We will conclude with reviews of how caching animals encode spatial information and the neural substrates for spatial memory in caching animals.

\section{The Natural History of Food Storage}

Animals face many problems obtaining food. Food may vary in abundance on a daily or seasonal basis, or even unpredictably, in boom-bust cycles. Even when food is abundant, there may be fierce competition for access to the food. And animals have evolved a number of strategies to cope with these problems, such as migration, hibernation, and torpor to deal with variability and food-caching and/or territoriality to deal with competition. Food hoarding is a strategy that can help an animal cope effectively with both variability in food availability and competition. By gathering food and hiding it, an animal can simultaneously store food against lean times and gain control over food against competitors.

Food storing takes many forms, from the nest of eusocial bumble bees to the grain silos of the human farmer (see Vander Wall, 1990, for a comprehensive review). The food storage patterns seen in nature vary considerably in the degree of dispersion among caches. At one extreme is larder-hoarding, in which food is gathered during times of plenty and placed into one or a few large larders. The hive and honeycombs of the honey bee (Apis mellifera) the granaries of acorn woodpeckers (Melanerpes formicivorus) or the middens of red squirrels (Tiamiasciuris hudsonicus) are excellent examples of this type of food storage. Once created, of course, these large caches require defense against competitors. Indeed, it would appear that one of the potential disadvantages of larder-hoarding is that loss of a larder incurs high cost to the original hoarder, since each larder site contains a large proportion of the animal's stored food.

The other extreme, in which food is stored in a large number of widely dispersed locations, is referred to as scatter-hoarding. Examples include fox squirrels (Sciuris niger) which store many of their walnuts singly; chickadees and tits, which store single seeds in moss and crevices; and nutcrackers, which store one to 14 pine seeds in each cache site. Larder- and scatter-hoarding define a continuum, not a dichotomy, and some mammals such as fox squirrels and yellow pine chipmunks (Tamias amoenus) store both singly and in larders (Vander Wall, 1990). These two storage strategies require quite different defense strategies. The scatter-hoarder creates more caches, each containing less food, over a much larger area than does the larder-hoarder. The caches of a scatter-hoarder cannot be physically; defended since they are highly dispersed, but the loss of any single cache site is much less significant for the scatter- than for the larder-hoarder. But scatter-hoarding does raise an interesting question, with intriguing cognitive possibilities. How does the scatter-hoarder relocate the large number of cache sites it has created?

Logically, there are three general classes of answer to this question. We present them in decreasing order of the cognitive demands needed for hoarders to successfully recover their own caches.

1. Memory for cache sites: If the hoarder could remember individual cache sites, it could then use this memory to recover the caches. This would, I however, require considerable memory capacity.

2. Site preferences or movement rules: Suppose an animal had certain locations that it preferred to visit or specific paths which it regularly followed, then stored food in those locations or along those paths. If it searched those places, it would be able to find the stored food at a much greater rate than could be achieved by random search. This strategy would require that the animal remember the preferred sites or paths, but it would not be necessary to remember individual cache sites. If, however, the site or path preferences could be learned by an observing competitor, then the potential for loss would be great.

3. Direct cues: The hoarder could relocate its food through detection of cues (such as odor) emanating directly from the cached food itself. While this recovery mechanism would require little cognitive ability except perhaps specialized sensory capacities, it would have a large potential downside. Any animal capable of detecting the cues could recover the cache, with potentially disastrous effects for the animal that originally created the cache.

Interestingly, there appears to be a negative correlation between the cognitive demands of the strategy and the resistance of the strategy to competitors for the caches. This implies that under appropriate conditions - a high risk of loss of scatter-hoarded food - the use of increased cognitive capacities might be favored, even though cog- 
nitive abilities involve heavy metabolic costs (Attwell and Laughlin, 2001).

The results of a field study of cache recovery and pilfering in small mammals (Vander Wall, 2000) is quite interesting from this point of view. Vander Wall allowed some yellow pine chipmunks (Tamias amoenus) or deer mice (Peromyscus maniculatus) to cache pine seeds in a large outdoor cage and then search for their own caches (knowledgeable foragers), while additional animals searched for caches created by others (naïve foragers). The experiment was conducted in the Carson mountain range of western Nevada, where the climate is usually quite dry. Under dry conditions, knowledgeable animals were much more successful finding their own caches than naïve animals searching for the caches of others. When conditions were wet, such as following rain, however, the chipmunks and mice found all caches, their own, those of conspecifics, or those of the other species, with equal facility (Figure 1). The superiority of the knowledgeable over the naïve cachers under dry conditions demonstrates the advantage that detailed spatial memory can give. On the other hand, the ability of the naïve foragers to locate the caches created by others demonstrates the potential liabilities of relying on direct cues to relocate cache sites.

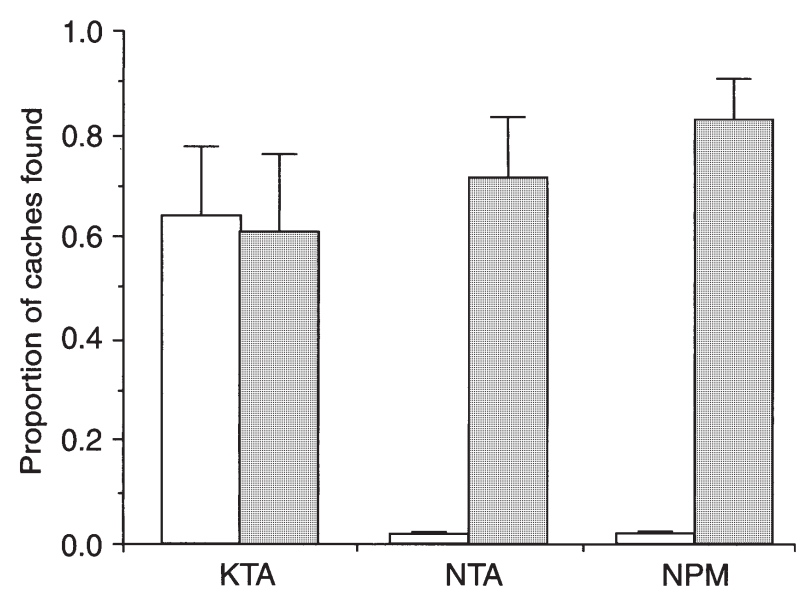

Figure I. The proportion of caches found by yellow pine chipmunks (TA) and deer mice (PM) who either knew the locations of the caches $(K)$ or were naïve about the cache locations $(N)$ under either dry conditions (open bars) or wet conditions (filled-in bars). From Vander Wall SB (2000) The influence of environmental conditions on cache recovery and cache pilferage by yellow pine chipmunks (Tamias amoenus) and deer mice (Peromyscus maniculatus). Behav. Ecol. I I: 544-549; used with permission from Oxford University Press.

\section{Establishing the Role of Memory}

Until recently, it was thought unlikely that scatter-hoarders used spatial memory for the recovery of cached food (e.g., Gibb, 1960). Gradually, however, evidence mounted that spatial memory for specific cache sites could be important to accurate cache recovery in a number of species of birds and mammals. Field studies provided suggestive evidence. For example, Tomback (1980) developed a technique for roughly estimating the accuracy of cache recovery by Clark's nutcrackers (Nucifraga columbiana) in the field. Tomback's estimated probabilities were quite high, much higher than could be expected by chance. In another field study, Cowie et al. (1981) placed mildly radioactive seeds in a feeder, and they were taken and cached by marsh tits and a scintillation counter used to locate cached seeds in the area around the feeder. A control seed was then placed 100 $\mathrm{cm}$ from each cached seed and survivorship of the seeds monitored. The cached seeds disappeared much more rapidly than control seeds, strongly suggesting removal by cachers and consistent with memory for specific cache sites.

MacDonald (1976) conducted similar experiments with a vixen, which almost always found dead mice she had cached but almost never found dead mice cached 1$2 \mathrm{~m}$ away by the experimenter.

\section{I Experimental Evidence for Spatial Memory}

Although these types of field studies yielded results consistent with the use of spatial memory for specific cache sites, field studies lack the capacity for experimental control necessary to fully rule out alternative hypotheses. The breakthrough came with a series of laboratory studies that showed that many parids and corvids would cache and recover seeds under laboratory/aviary conditions. In this section, we briefly review the major findings of some of these studies that established the role of spatial memory in the relocation of cached foods.

Balda (1980) tested a single Eurasian nutcracker (Nucifraga caryocatactes) in a room with a dirt floor. The bird readily cached and accurately recovered seeds in this room. The search was accurate even when seeds had been removed from caches before recovery, demonstrating that cues emanating directly from caches were not necessary for recovery. Vander Wall (1982) extended these findings by letting two Clark's nutcrackers individually cache and recover cached seeds in the same avi- 
ary. In virtually every case, each bird recovered only its own caches. This also provides strong evidence against direct cues, as well as against site preferences or paths unless these are idiosyncratic.

At the same time as studies were proceeding with nutcrackers, researchers in Canada and England were developing laboratory-based procedures to study cache recovery in chickadees and tits. Sherry et al. (1981) gave marsh tits (Parus palustris) sunflower seeds to store in moss-filled trays in an aviary. The birds revisited the areas of the trays used to cache seeds significantly more often than would be expected by chance 3 and $24 \mathrm{~h}$ after original storage of the seeds, even though the seeds had been removed. Sherry et al. (1981) also found that the probability of visiting those quadrants in which cache sites were located was higher following caching than it had been during a precaching exploratory session, suggesting that site preferences were not responsible for the performance. Sherry (1984) extended these results in an aviary study with black-capped chickadees (Parus atricapillus) by giving the birds specific potential cache sites (as opposed to areas in a tray). The chickadees cached readily in these sites and recovered the caches more accurately than would be expected by chance or by precaching exploratory patterns.

Kamil and Balda (1985) took a more direct approach to the control of site preferences during cache recovery by Clark's nutcrackers. They used a room with 180 holes in the floor, each of which could either be filled with sand for caching/recovery or be capped with a wooden plug. This made it possible to limit the number of sites available for caching sessions, forcing the birds to cache in sites essentially chosen by the experimenters. Even under these conditions, nutcrackers were able to recover caches accurately, demonstrating that site preferences are not necessary to accurate cache recovery by nutcrackers.

Three studies in the early 1990s demonstrated the use of spatial memory to relocate caches in scatter-hoarding rodents. Jacobs and Liman (1991) had gray squirrels cache hazelnuts in an outdoor arena. The squirrels found significantly more of their own caches than the caches of other squirrels that had stored food in the same arena. Vander Wall (1991) allowed yellow pine chipmunks to cache seeds in an arena filled with dry sand. The chipmunks were significantly more likely to find their own caches than caches of other chipmunks. Jacobs (1992) allowed Merriam's kangaroo rats to cache and retrieve sunflower seeds in an arena with plastic cups filled with sand for caching sites (much like Kamil and Balda, 1985). Before retrieval, she removed half of the caches made by each rat. The rats searched significantly more in locations where they buried seeds, whether the seeds had been removed or not. Jacobs also found that a naivve rat searching in the arena found significantly fewer caches than the rat that had made the caches.

It is clear that some form of spatial memory for cache sites is used to find cached seeds by members of several taxa (see Vander Wall, 1990, for a broad survey of foodhoarding in animals). Although other mechanisms such as olfaction or site preferences may play a role, many food-storing corvids and parids and rodents can find their food when these mechanisms are controlled for or eliminated. We now turn our attention to what is known about spatial memory in food-storing species.

\subsection{The Characteristics of Cache Memory and Retrieval}

It seems likely that the characteristics of cache site memory in any particular species of scatter-hoarders will be a function of a complex interaction between functional and mechanistic variables. For example, as caches are created, they are necessarily created in some sequence. A large psychological literature indicates that in the case of such serial lists, the order in which the items to be remembered are presented can have important effects on how well they are remembered, the serial position effect well known to students of memory (e.g., Wright et al., 1984; Wright, 2006). On the other hand, different orders of recovery may be most adaptive under different circumstances (Andersson and Krebs, 1978). Duration of memory may be another example. In this section, we briefly survey what is known about the duration, contents, and dynamics of cache memory.

\subsection{Memory duration}

Balda and Kamil (1992) tested four groups of nutcrackers, each at a different amount of time after caching, from 11 to 285 days. All four groups performed well above chance levels. Bednekoff et al. (1997a) used a repeated-measures design in a comparative study with nutcrackers, pinyon jays (Gymnorhinus cyanocephalus), Mexican jays (Aphelocoma ultramarina), and Western scrub jays (A. californica; note that the classification of Aphelocoma species was modified several years ago; 
we use the current nomenclature throughout this chapter) and found that the birds were still performing above chance after 250 days. In contrast, most studies with parids have suggested much shorter memory durations. For example, Hitchcock and Sherry (1990) found that black-capped chickadees did not find their caches at better than chance levels after postcaching intervals over 28 days, and Brodin and Kunz (1997) obtained similar results in willow tits (Parus montanus).

These differences in memory duration correspond with differences in natural history. Many corvids cache in the fall and then depend on their cached food throughout winter into the spring (Vander Wall, 1990). In contrast, within the parids many species cache for shorter periods of time, caching and recovering throughout the winter (e.g., marsh tits, P. palustris; Cowie et al., 1981), although there are some parids that cache in fall and use those caches for some months (e.g., crested tits, P. cristatus; Haftorn, 1954). Brodin (2005) has suggested that corvids possess a site-specific, accurate long-term memory, whereas parids may use a more general memory along with area-restricted search.

\subsubsection{Memory for cache contents}

Several studies indicate that cachers can remember the contents of their caches. Sherry (1984) allowed blackcapped chickadees to cache two types of seed and found that they recovered the type they preferred before the nonpreferred type. Clayton and Dickinson (1999) extended this methodology by allowing Western scrub jays to cache two types of food, then prefeeding one of the foods before recovery testing. During recovery, the birds preferentially searched sites in which they had cached (but not retrieved) the food that had not been preferred (See Chapter 1.23, research by Clayton and her colleagues on episodic-like memory). This suggests a memory process more dynamic than a simple association of foods and the locations of their caches.

Moller et al. (2001) gave Clark's nutcrackers small and large pine seeds to cache and videotaped recovery sessions. They measured the size of the gape, the distance between the upper and lower bills when beginning to dig out the cache. Gape size was reliably larger for caches containing the larger seeds than for caches containing the smaller seeds.

\subsubsection{Order of recovery}

As a number of authors have pointed out (e.g., Vander Wall, 1990), since caches are created sequen- tially, the psychological literature on memory suggests that there ought to be some relationship between order of cache creation and order of cache recovery, either primacy (first recovering the caches that were created first) or recency (first recovering the most recently made caches). Psychological studies of memory for serial lists regularly find both of these effects in a wide variety of contexts in humans and animals (see recent review by Wright, 2006).

It has also been argued on functional grounds that there should be recency effects in cache recovery (e.g., Shettleworth and Krebs, 1982). The more time that has passed since a cache was created, the less likely that cache is to still be available to the cacher. As time passes, the probability of the cache having been pilfered increases and the chances of the cache location having been forgotten also may increase. Thus, recovery of the most recent caches first could maximize the total number retrieved. There has, however, been no consistent evidence of such effects. For example, when blackcapped chickadees stored and recovered sunflower seeds in Sherry (1984, experiment 2), 24 correlation coefficients between cache and recovery orders were calculated. Two were significant in the positive direction, one was significant in the negative direction, and the remainder were not significant.

In a comparative study with Clark's nutcrackers, pinyon jays, and western scrub jays, Balda and Kamil (1989) calculated 42 correlation coefficients between cache order and recovery order. Twenty-five were above zero, one equaled zero, and the remaining 16 were below zero. Six of the positive correlations were significant, as was one of the negative correlations, indicative of a tendency toward recency effects, which was not statistically significant overall.

\subsubsection{Proactive and retroactive interference}

Serial position effects are often interpreted as due to the effects of interference, at least in part (see Shettleworth, 1998, for discussion; see also Chapters 6 and 10 in Learning and Memory: A Comprehensive Reference, Volume I (2008), ed. R. Menzel). Two types of interference are generally recognized. If the target information was experienced before the interfering information, the effects of the interfering information are called retroactive interference. If the target was experienced after the interfering information, it is called proactive interference. As might be expected from the failure to find strong serial-position effects during cache recovery, attempts to 
document retroactive and proactive interference during caching have also yielded only weak evidence for such effects. Bednekoff et al. (1997b) explicitly tested for interference in nutcrackers' cache memory by allowing caches to be made at different times. They found no evidence of interference between the two sets of caches.

Experiments using techniques other than cache recovery have found clear evidence for interference effects in parids and corvids. For example, when black-capped chickadees were presented with three-item lists in an operant associative task, they showed clear primacy and recency effects (Crystal and Shettleworth, 1994). And when Lewis and Kamil (2006) gave Clark's nutcrackers separate lists of locations to remember, they showed clear retroactive and proactive interference effects between the lists. These results raise the question of why such effects are weak in cache recovery but prevalent with other measures of memory performance.

\subsubsection{Dynamism of memory}

As caches are recovered, an additional problem arises: not only are there caches to remember but there are emptied caches to avoid. Do cachers avoid revisiting sites which have been emptied? Sherry (1982) examined this question by allowing marsh tits to cache in mossfilled trays then recover about half these caches $3 \mathrm{~h}$ later. Twenty-four hours after the initial caching, he allowed the tits to recover more caches. The birds clearly made more visits and spent more time at sites which had been cached in but not recovered from than sites that had been cached in and recovered from. Sherry (1984, experiment 2) obtained similar results in black-capped chickadees.

Frequent revisits to emptied cache sites have been observed in Clark's nutcrackers (e.g., Balda, 1980; Kamil and Balda, 1985). These studies, however, were not primarily intended to measure revisit probabilities against appropriate controls, so the implications of the frequent revisits were not clear. Balda et al. (1986) found that revisits to emptied caches by nutcrackers were much more frequent than expected by chance, and that revisit probability was not affected either by leaving signs of previous recoveries on the surface of the sand around cache sites or by reducing the number of seeds in a cache.

From a functional perspective, these observations are a puzzle since revisits increase foraging effort and may also increase predation risk. These considerations led Kamil et al. (1993) to take another look at revisits by Clark's nutcrackers, using a technique which allowed independent estimates of search accuracy and of preference. When they tested sites with cached seeds (good sites) vs. sites with cached seeds that had been removed by the birds (old sites) vs. holes that never had seeds in them (bad sites), the results clearly demonstrated that nutcrackers treated old sites differently than good sites. When they visited a cluster that contained an old site, they probed more of the alternative sites than when they visited good sites that contained seeds. In addition, they visited clusters containing good sites earlier than those containing old sites. They also found that old sites were visited earlier than clusters containing bad sites. Once the good sites have been exploited, the birds are more likely to visit old sites where they cached and then removed seeds than to visit bad sites that never contained seeds.

\subsubsection{Are all caches created equal?}

In the Balda and Kamil (1992) study of long-term memory for cache sites, the group of birds tested at the longest cache-retrieval interval showed an interesting pattern of errors. Their error rate per recovery was approximately equal to that of the groups with the shorter retention interval until about $75 \%$ of their caches had been recovered. After that, they began to make more errors. This pattern suggested that after 280 days, the nutcrackers had begun to forget some of their cache locations and had recovered those that they remembered most accurately first.

Kamil and Balda (1990) controlled the order of cache recovery by covering the floor in one-quarter of the caching room with canvas. Over four recovery sessions, each quarter of the room was covered once. The accuracy of recovery of this group was compared to that of a control group for whom all cache sites were always available. As predicted, the experimental group showed an initial recovery accuracy that was lower than that of the controls. But this accuracy level was constant over the four sessions, whereas the accuracy of the controls declined, so that during the fourth session the experimental group was more accurate than the controls. This clearly supports the hypothesis that some sites are remembered better than others, and then recovered first.

\subsection{Coding of Cache Site Locations}

When a scatter-hoarding animal remembers sites at which it has stored food, just what is it about the cache location that is remembered? Just how is the location encoded in memory? This raises basic questions about orientation and navigation. There is enormous literature 
on the cues that animals in a wide variety of taxa use to find locations during, for example, foraging, homing, or migration (see chapters 12, 20, and 25 in Learning and Memory: A Comprehensive Reference, Volume I (2008), ed. R. Menzel). In this section we will focus on studies that relate to how caching animals use landmarks to find locations and divide our review into studies that study cache recovery and studies that use other techniques.

\subsection{Landmark use during the recovery of stored food}

Many studies have demonstrated that landmarks play a crucial role in accurate cache recovery. For example, animals have been tested for their ability to find their caches when most or all of the landmarks present during caching have been removed from the teaching area during recovery testing. If landmarks are important, this should produce substantial decrements in the ability to relocate caches, and it does (e.g., nutcrackers, Balda and Turek, 1984; parids, Herz et al., 1994). Barkley and Jacobs (1998) took a slightly different approach, allowing Merriam's kangaroo rats to cache and recover with either no or with many landmarks present. While the number of landmarks had no effect after a 1-day retention interval, there were large effects after 10 days. The kangaroo rats that had cached and recovered with no landmarks performed at much lower levels than those who had cached and recovered with 16 landmarks present. While such studies establish the role of landmarks in cache recovery, they tell us little about what mechanisms might be used. Few studies, however, have attempted to determine the mechanisms that are used during cache recovery.

The first attempt to do so of which we are aware was by Bossema and Pot (1974). They compared the routes used by individual Eurasian jays (Garrulus glandarius) when making and recovering caches. They found that the jays tended to use the same route during recovery as during caching more often than would be expected by chance. Bossema and Pot suggested that the birds used a snapshot of the scene from the cache site when they cached, then matched what they saw to the snapshot during recovery.

Kamil et al. (1999) found the Bossema and Pot interpretation unconvincing. There are many other reasons that could result in use of the same path during caching as during recovery. They conducted an intensive videotape study of movement patterns by nutcrackers during caching and recovery, using a technique that allowed estimates of the accuracy of recovery of each individual cache. Like Bossema and Pot (1974), Kamil et al. (1999) found that the birds tended to frequently use the same path during caching and recovery, but differing paths and body orientations were also often used. Because their procedure allowed cache-by-cache estimates of accuracy, Kamil et al. (1999) were able to determine the effect of consistency of direction on recovery accuracy. There were none: Birds were equally accurate regardless of the path used. This result argues directly against the snapshot hypothesis.

Bossema (1979) looked at the locations of caches and the accuracy of recovery relative to the positions of landmarks. He found that Eurasian jays cached more near vertical objects and were more accurate at retrieving their caches when vertical objects were available as beacons, as opposed to horizontal objects. Similar results have been found in studies in which caching animals have been trained to find food in specific locations (see following). In a second test, he taught the birds to find hidden food in a specific spatial location relative to two vertical landmarks. He performed tests in which one landmark was removed or the landmarks were moved further apart or closer together. From these tests, he concluded that the jays were using the distance between the spatial location and the line between the landmarks to orient.

Vander Wall (1982) took a different approach. After Clark's nutcrackers had cached food in an arena with an array of landmarks, he displaced the landmarks in one half of the room $20 \mathrm{~cm}$ from their original location during cache recovery (Figure 2). During the subsequent recovery session, the birds shifted their searching approximately $20 \mathrm{~cm}$ in the direction of the displacement in that half of the room. When the birds searched for caches made in the center of the room, where some of the nearby landmarks had been displaced and others had not, their search was displaced approximately $10 \mathrm{~cm}$ in the direction of the displacement. This suggests that the birds were integrating information from multiple landmarks (shifted and nonshifted) and searching at some kind of averaged location.

One of the ways to use landmarks to find a location is to use the directional relationship between the cache site and one or more landmarks (e.g., Kamil and Cheng, 2001). The use of directional information requires a compass. In a series of studies, Wiltschko and Balda (1989) and Wiltschko et al. (1999) have used clock-shift procedures in outdoor aviaries to demonstrate the use of a sun compass by scrub jays and nutcrackers. For example, Wiltschko and Balda (1989) had scrub jays cache 

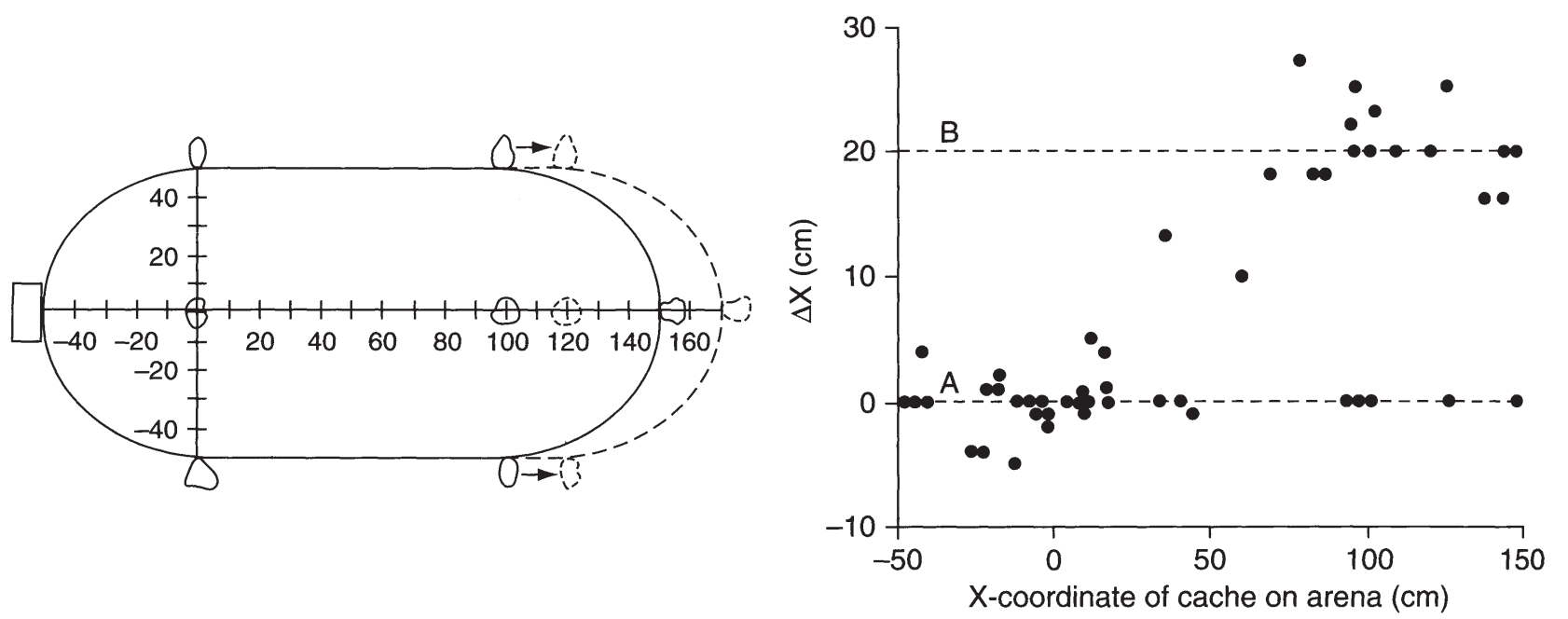

Figure 2. The left panel shows the caching arena during control (solid lines) and during landmark-shift (dashed lines) conditions. The right panel shows the distance between a probe and the nearest cache on the $y$-axis as a function of the original position of the cache in the $x$-axis. If the birds followed the shift, a $\Delta x$ score of $20 \mathrm{~cm}$ would be expected. Reprinted from S. B.Vander Wall,"An experimental analysis of cache recovery in Clark's nutcracker,' Animal Behaviour 30 (1982), 84-94, copyright 1982, with permission from Elsevier.

in a $90^{\circ}$ sector of a circular outdoor arena and then recover after being clock-shifted $6 \mathrm{~h}$. When clock-shifted, the search was concentrated in an adjacent $90^{\circ}$ sector, as would be expected if the sun compass was being used. Although these experiments clearly establish the use of sun compass under some conditions, caches can be recovered in the absence of information from the sun (e.g., indoors). Furthermore, when multiple landmarks are used to encode locations, clock shifts should produce conflicting effects (Kamil and Cheng, 2001).

Another issue that has been investigated both during cache recovery and during other tests of spatial memory in seed-caching animals is the relative importance of local versus global (or distal) cues. Local cues are those located relatively close to the goal location, while global or distal cues are generally larger, but further away. Several studies have found that birds seem to have some preference for caching near objects in the environment, suggesting that local cues may be quite important (e.g., Bossema, 1979). On the other hand, Balda et al. (1986) found that Clark's nutcrackers ignored local cues on the surface when making revisits to cache sites. The results of Herz et al. (1994) suggest the importance of global cues. Black-capped chickadees stored food on artificial trees placed within a symmetrical enclosure that had large global cues on each wall. There were unique color place cues located by each potential cache site. The removal of the place cues did not affect retrieval accuracy, but when the global cues were removed, search accuracy decreased. In a second study, when birds were only given global cues during caching, displacement of those cues during recovery produced a displacement of the search behavior. Watanabe (2005) has also shown the importance of global cues in remembering cache locations in Western scrub jays.

Results from mammals also suggest distal cues are important. Lavenex et al. (1998) found that fox squirrels use distal environmental cues rather than proximal cues to find food in a field experiment. Even when proximal spatial information was available, the squirrels chose to use the environment surrounding the apparatus to gain spatial information, presumably directional information or bearings. Jacobs and Shiflett (1999) devised an outdoor vertical maze to mimic the vertical structure of the squirrel's environment. They found that fox squirrels used distal cues to orient within this maze as well.

\subsubsection{Landmarks and the coding of spatial locations}

Cache recovery procedures are very limited for studies on how cachers encode spatial locations. As several of the studies reviewed suggest, the geometrical relationships among landmarks and between landmarks and the location of a cache are important. But it is very difficult to control location-landmark geometry when the caching animal is free to cache throughout the test arena. Therefore, many investigators have used procedures in which animals are trained to find buried food in a location defined by a set of local/global landmarks or other cues. 


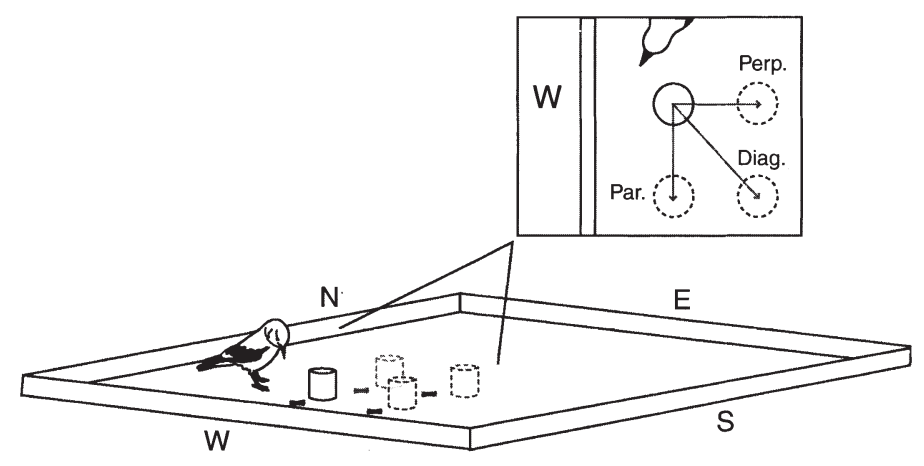

Figure 3. Typical setup (not to scale) for experiments on landmark displacement with an edge and a single landmark present. The birds are initially trained with the cylinder in the location indicated by the solid circle (top left in the inset). They are then tested with occasional nonrewarded trials at each of the three test positions, representing displacements perpendicular (Perp.), parallel (Par.), and diagonal (Diag.) to the long axis of the nearest edge. Drawing by Karina I. Helm.

Bennett $(1993 a, b)$ trained Eurasian jays to find hidden food within an array of landmarks on the floor of an arena. The array consisted of landmarks that were either short or tall and either near or far from the hidden food location. He found that the birds relied more heavily on near, tall landmarks to find the food, a finding similar to that of Bossema (1979), described in section 3.3.1, "Landmark use during the recovery of stored food." This suggests that local cues are most important, especially if tall.

Other experiments, however, suggest that low horizontal features that define an edge can also be important. Cheng and Sherry (1992) trained black-capped chickadees to find food buried in a location defined relative to the locations of a cylindrical landmark and an edge (Figure 3). Then, when the landmark was shifted in a direction either parallel or perpendicular to the edge during probe trials, the birds followed parallel shifts more strongly. This was particularly clear during probe trials in which the landmark was shifted in a diagonal direction, which produced more parallel than perpendicular shifts in search. As Cheng and Sherry pointed out, these results suggest that perpendicular distance from an edge can serve as an important means of encoding spatial locations and are consistent with the results of Bossema (1979).

Similar studies with Clark's nutcrackers (Gould-Beierle and Kamil, 1996, 1998), pinyon jays, and scrub jays (Gould-Beierle and Kamil, 1998) have also found that the distance from an edge is important. In all three of these studies, birds found hidden food whose location was defined relative to the locations of an edge and a cylindrical landmark. As in the parids studied by Cheng and Sherry (1992), these corvids followed parallel shifts and shifted more readily in the parallel direction when given diagonal shifts. However, when the landmark was shifted in a direction perpendicular to the edge, nutcrackers, pinyon jays, and scrub jays did not shift their searching in that direction, in contrast to the results of Cheng and Sherry (1992).

Gould-Beierle and Kamil (1998) extended the conditions originally tested by Cheng and Sherry (1992) by testing the effects of varying the position and orientation of an edge and landmark across training trials with nutcrackers, pinyon jays, and scrub jays. Following this training, the birds were more sensitive to shifts in the position of the cylindrical landmark, shifting their search with each landmark shift to a much greater extent than birds trained with a nonshifting edge and landmark. The shifting of the relationship between the local cues (edge and cylinder) and the global cues (features of the room) appeared to result in a devaluation of both the global cues and distance from the edge. The extent to which distance from a line or edge is used thus depends upon the salience and location of other, more distal or global landmarks.

The relative importance of local versus more distal or global cues depends on context and on the distance between the local cues and the target location. GouldBeierle and Kamil (1999) trained three groups of Clark's nutcrackers to find a hidden food site within an open room filled with wood chips. Two local cues were available near the food site, a cylindrical landmark and a horizontal piece of wood (much like the edge of a tray in previous studies). The groups varied in the distance the cylinder and edge were from the target location. They 
found that the group with these cues closest to the target used them more heavily to find the location, while the other two groups relied more on information from global cues within the room.

Goodyear and Kamil (2004) extended these results with a study in which different groups of Clark's nutcrackers were trained to find a buried seed at a location defined by an array of four landmarks, each of which was at a different distance from the goal, followed by probe tests with each of the individual landmarks. The groups differed in the mean distance from the landmarks to the goal location. For the group for whom the nearest landmark was quite close to the goal, the presence of the closest landmark had the greatest effect on search accuracy, an effect reminiscent of the overshadowing effect in Pavlovian conditioning (Gallistel, 1990). However, at longer goal-landmark distances, this overshadowing effect disappeared, and each landmark controlled search roughly equally.

Since geometry clearly affects search, there has been some interest in the ability of caching animals to directly learn geometric relationships. Kamil and Jones (1997) tested the ability of Clark's nutcrackers to learn a general geometric rule for spatial locations. They trained nutcrackers to find a seed that was always located halfway between two landmarks whose position in the room and interlandmark distance varied from trial to trial. The birds learned the task readily and searched extremely accurately when tested with new interlandmark distances. Follow-up studies demonstrated that nutcrackers could learn other geometrical rules (Kamil and Jones, 2000), including the use of relative bearings Jones and Kamil, 2001). Comparative studies found that nutcrackers performed these tasks much more accurately than pigeons (Jones et al., 2002; Spetch et al., 2003).

One of the things that makes the location of cached food so interesting from a coding/navigation and orientation perspective is that successful cache recovery requires a very accurate search. Given the size of a nutcracker's beak and the size of pine seeds, for example, the bird must dig within 1-2 cm of the center of a cache in order to find it. This led Kamil and Cheng (2001) to hypothesize that nutcrackers encode the directional relationship between the goal and multiple landmarks. This was based on a combination of known features of search accuracy and a logical consideration. When nutcrackers are looking for a cache site that is not close to a landmark, the use of directional information results in a more accurate search than the use of distance information.
But all compasses have error, and compensation for such error can be achieved by taking bearings to multiple landmarks. Although there are some data that support the model (Kamil et al., 2001), there are, as yet, insufficient data to fully evaluate the hypothesis.

\section{The Evolution of Spatial Memory in Seed- Caching Animals}

The capacity, duration, and dynamics of the memory that seed-caching animals use to relocate stored food seem quite impressive compared to the results of many studies of animal memory using standard psychological procedures such as the radial maze or matching-tosample (see Chapters 20, 21, 23, 25, and 26 in Learning and Memory: A Comprehensive Reference, Volume I (2008), ed. R. Menzel). This led to the development of the hypothesis that dependence on memory for the location of cached food would be associated with heightened memory abilities. This hypothesis, sometimes referred to as the ecological hypothesis, has led to many studies of memory comparing species that differ in their degree of dependence on cached food. We will divide our review of this literature by methodology, first discussing studies that used cache recovery as their measure of memory, then reviewing studies that used measures of spatial memory that do not depend on the caching and recovery of food.

\section{I Cache-Site Memory}

There are relatively few comparative studies involving cache site memory. This is probably because such studies require the availability of a set of closely related species (or populations) which cache, but vary in some dimension of cache-related natural history, and there are few such instances. We are only aware of four such studies, two with corvids and two with parids.

Balda and Kamil (1989) compared the cache recovery accuracy of three corvid species that differ in their degree of dependence on stored food, Clark's nutcrackers, pinyon jays, and Western scrub jays, after a relatively short retention interval of 7 days. They found that the more cache-dependent species, nutcrackers and pinyon jays, recovered their caches more accurately and more rapidly than Western scrub jays. Bednekoff et al. (1997a) tested the same three species as well as Mexican jays after retention intervals of 10-250 days. They found that cache recovery performance of the two Aphelocoma spe- 
cies (Mexican and Western scrub jays) was lower that that of the nutcrackers or pinyon jays, but that all four species performed with only modest accuracy levels (although still significantly better than chance) after the two longest retention intervals (of 150 and 250 days).

Healy and Suhonen (1996) compared marsh tits and willow tits. Willow tits live in harsher environments than marsh tits and are thought to retrieve their caches after longer retention intervals than marsh tits. In this study, however, no differences in the accuracy of cache recovery were found after either a short (1- to 2-h) or a long (17-day) retention interval. Pravosudov and Clayton (2002) compared two populations of black-capped chickadees, one from Alaska and the other from Colorado. They found that the birds from the harsher environment of Alaska cached more food and recovered it more efficiently than the birds from Colorado, demonstrating that different ecological pressures within this single species are correlated with differences in spatial memory ability. Thus three of these four studies found differences in cache recovery accuracy that were correlated with differences in dependence on stored food.

\subsection{Noncache-Site Memory}

Most comparative work on spatial memory involving scatter-hoarding species has been based on procedures that do not depend on caching. Such procedures are necessary to compare spatial memory between caching and noncaching species. In addition, data from such tests could address the question of just how specialized the spatial memory abilities of food-caching animals may be. A variety of techniques were applied, and we have organized our review of these comparative studies by the procedures used to test memory.

\subsection{Window shopping}

The window shopping task is probably the noncaching task most similar to cache memory. Instead of storing food in a location to be remembered, the bird encounters the seed, either behind a transparent window or a seed wedged into a small hole so tightly that it cannot be removed. Shettleworth et al. (1990) showed that memory for such encountered seeds appeared to be similar to that for stored seeds in black-capped chickadees and coal tits. Krebs et al. (1990) used the technique to test coal tits against nonstoring great tits. They found somewhat better performance in the storing coal tits. Coal tits were more likely than great tits to return to sites at which they had seen seeds. They were also better at discriminating between sites seen to contain seeds and those seen to be empty.

\subsubsection{One-trial associative tasks}

In one-trial associative tasks, two or more stimuli are all associated with a correct location. Following a single experience at that location, the subject is given test trials in which it chooses between the spatial location or the nonspatial stimuli (which are now presented in a new location; see Figure 4). A number of one-trial associative studies have used a variation of window shopping in which the bird finds food at a specific location which is also indicated by cues from an object. The bird is allowed to begin to eat, but is interrupted (removed from the experimental situation) before completely consuming the food. The test is to see where the birds will return to look for the seed, to the correct spatial location or the correct location based on object cues. In comparisons of food-storing and nonstoring species in both parid and corvid families (Clayton and Krebs, 1994), the food-storing birds (marsh tits and jays) went first to the correct spatial location, whereas the nonstorers (blue tits, Parus caeruleus, and jackdaws, Corvus monedula) went equally as often on their first choice to the correct spatial or object-specific location. When comparing food-storing chickadees to nonstoring dark-eyed juncos (Junco hyemalis), Brodbeck (1994) found similar results, with the chickadees responding preferentially to spatial cues and the juncos responding equally to spatial and object cues. These studies provide further evidence that food-storing birds focus heavily on spatial memory when returning to food sites.

In another variation on this theme, Brodbeck and Shettleworth (1995) placed spatial and object-related cues in conflict in the choice phase of test trials in a matching-to-sample experiment. With this technique, they found that while space was the first choice of foodstoring chickadees, nonstoring juncos chose space and color equally. They also demonstrated that when shown a compound stimulus of both spatial location and color and tested on each element of the compound alone, chickadees performed better on the spatial element, while juncos performed equally well on both elements. This, along with the other one-trial associative memory experiments, demonstrates the importance of spatial information to food-storing birds. 


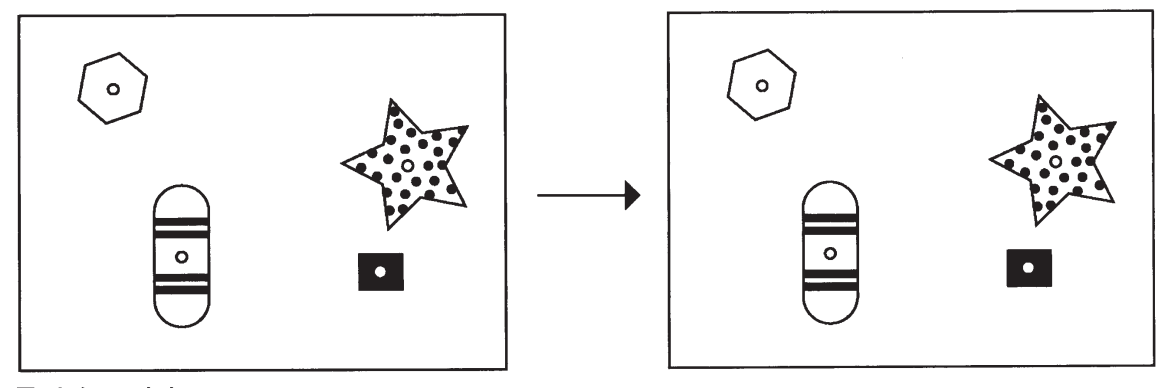

Training trials

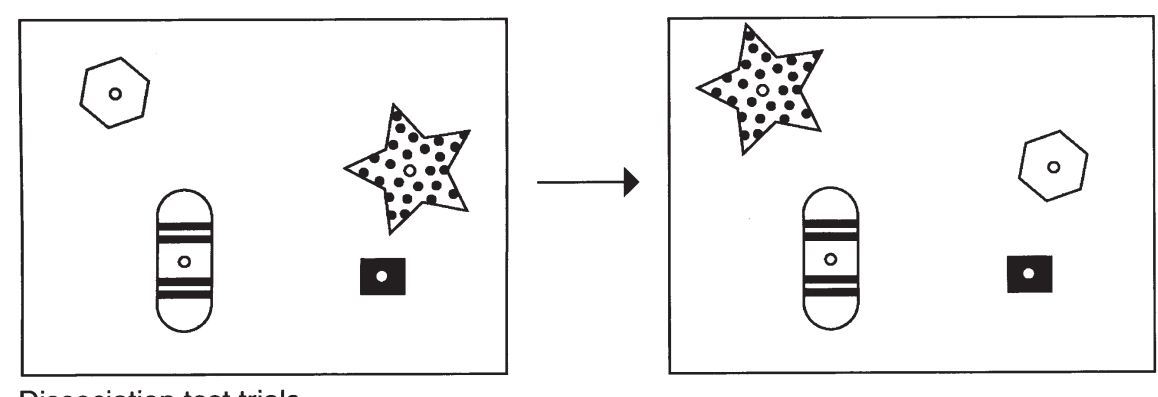

Dissociation test trials

Figure 4. Diagrammatic representation of the logic of one-trial associative tasks. The top pair of figures shows training trials. One of the stimuli is randomly designated correct on each trial (with new, trial-unique stimuli used for each trial). The bird is then rewarded when it pecks the correct stimulus. The display then disappears for a retention interval, and the same display is presented for choice, and the bird is rewarded for pecking at the same stimulus. Once this training is complete, the bird receives occasional dissociation test trials, as shown in the bottom pair of figures. These trials differ from training trials in that the spatial locations of two of the stimuli are switched. If the bird pecks at the same visual stimulus (the dot-filled star, in this case), this indicates control by the stimulus. But if the bird pecks at the old location (the hexagon), it suggests spatial control. Spatial location and visual stimulus have been dissociated. Drawings by Karina I. Helm.

Lavenex et al. (1998) used an approach similar to that of one-trial associative tests in a field experiment. Although their training task involved multiple trials, they gave fox squirrels different spatial and nonspatial relational proximal cues that could be used to predict the locations of nuts buried by experimenters. The squirrels used spatial over nonspatial information to solve the task, even when both were available, a result similar to the results of laboratory one-trial associative experiments just reviewed.

\subsubsection{Open-room radial maze}

In an open-room radial maze procedure, Hilton and Krebs (1990) tested two storing parid species, two nonstoring parid species, and a nonstoring greenfinch in an openroom analog of the radial maze. They found decreasing performance as the retention interval increased from 30 $\mathrm{s}$ to $24 \mathrm{~h}$. The food-storing tits (marsh and coal tits) performed above chance after $24 \mathrm{~h}$, although the extent to which their performance exceeded chance was modest. In contrast, neither the nonstoring tits (blue and great tits) nor the finches performed above chance after $24 \mathrm{~h}$.
Kamil et al. (1994) tested four corvids who vary in dependence on stored food in their version of an openroom analog of the radial maze. They found that the two species most dependent on stored food, Clark's nutcrackers and pinyon jays, acquired the task to higher levels than the less dependent species, Mexican and Western scrub jays. When retention intervals of 30-300 min were tested (in ascending order), the species differences tended to disappear as the retention interval got longer. Only the most dependent species, the nutcrackers, performed above chance after a 24 -h retention interval, although, as in the marsh and coal tits, their performance was only modestly better than chance.

Gould-Beierle (2000) also tested four corvid species nutcrackers, pinyon jays, Western scrub jays, and jackdaws - on a version of the open-room radial maze task. She included both a reference memory and a working memory component by having 12 holes in the floor, four of which were never correct while the other eight were used in the usual way as working memory locations. She found that pinyon jays and scrub jays performed better than nutcrackers and jackdaws in both the working and 
reference memory aspects of the procedure. When looking at the first four searches in the maze, however, the nutcrackers performed as well as the two jay species in working memory and there were no species differences in reference memory. The performance of the scrub jays was not expected and suggests further exploration into the spatial memory abilities of this species. Perhaps combining both a working and reference memory task simultaneously affects spatial memory differentially in these species.

Barkley and Jacobs (2007) used an open-room task similar to a radial maze analog. They trained two species of kangaroo rat in a task in which the animal was shown four locations (randomly chosen out of 128) and then tested for their ability to remember the four $24 \mathrm{~h}$ later. One species was the scatter-hoarding Merriam's kangaroo rat (Dipodomys merriami), a species that hoards intensively. The other was the leaf-eating specialist Great Basin kangaroo rat (D. microps), which relies less on scatter-hoarding than Merriam's. Merriam's kangaroo rat performed considerably better than the Great Basin kangaroo rat on this task.

\subsubsection{Operant tasks}

A number of investigators have used several different operant tasks to measure differences in memory ability among storing species and between storing and nonstoring species. The most commonly used procedure has been spatial delayed nonmatching- or matching-tosample. In this task, each trial consists of two parts: the presentation of the sample followed by the presentation of a choice test. Thus, for example, Olson $(1989,1991)$ had two keys on the front wall of an operant chamber. Each trial began with the illumination of one of those keys, chosen at random on each trial. After the bird had pecked at that key and moved to the back of the box to peck at another, single key located there (to break up any patterns of settling in front of the to-be-correct key), the bird was presented with two keys and rewarded only for pecking at the key that had not been pecked at earlier in the trial (nonmatching). Olson (1989) tested Clark's nutcrackers, scrub jays, and pigeons (Columba livia). Although all three learned the task with equal facility, the nutcrackers outperformed the other two species when the task was made more difficult by either titrating the delay between sample and choice test or by introducing multiple samples to be remembered.

These results were extended in a subsequent study (Olson et al., 1995) with nutcrackers, pinyon jays, scrub jays, and Mexican jays. In this study, a computer monitor and touch screen were used. When the delay interval was titrated, the nutcrackers performed at much higher levels than the other three species. After completing this spatial nonmatching test, the birds were then tested on an almost exactly equivalent nonspatial task. In this experiment, the samples could be either red or green and the bird had to remember the color rather than the location. Under these conditions, the ordering of the species changed completely, and none of the species differences were statistically significant (Figure 5).

(a)

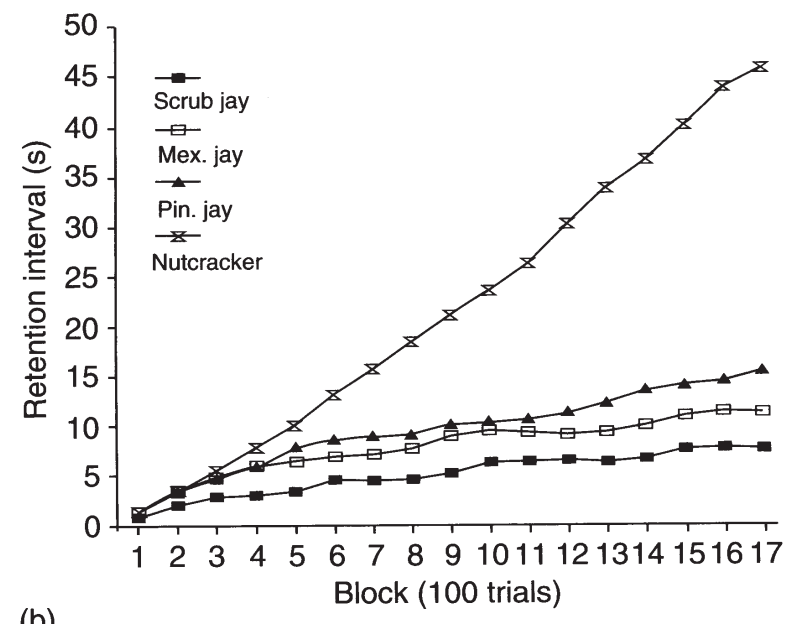

(b)

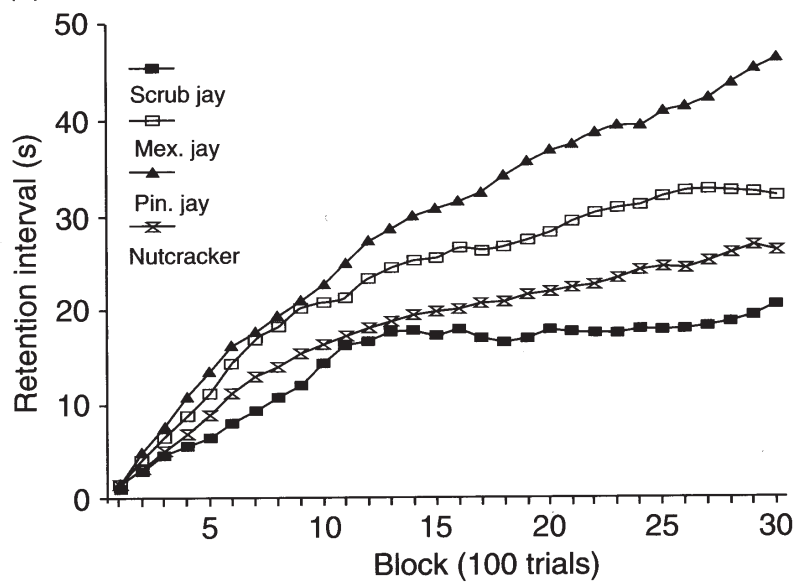

Figure 5. (a) Performance of scrub jays, Mexican jays, pinyon jays, and nutcrackers during spatial nonmatching-to-sample titration. (b) Performance of each species during color nonmatching-to-sample titration. Data are presented as averages of blocks of 100 trials. From D. J. Olson, A. C. Kamil, R. P. Balda, and P.J. Nims, "Performance of four seed-caching corvid species in operant tests of nonspatial and spatial memory," Journal of Comparative Psychology 109 (1995), Pp. 173-18I; used with permission from the American Psychological Association. 
Healy and Krebs (1992) studied matching-to-sample in marsh tits and great tits, using a choice apparatus attached to the birds' home cage. The birds took a seed from the correct location, which was signaled both by location and by a visual object, then returned to their home cage to consume the object. They were then given a choice test, and the two species performed very similarly. The only significant different between the species was superior performance by the storing marsh tits early in acquisition of the task. Healy (1995) used a more traditional nonmatching-to-sample (NMTS) test on a computer monitor with four parid species, two storing species (coal and marsh tits) and two nonstoring species (blue and great tits). The birds performed well at retention intervals as long as $100 \mathrm{~s}$, but there were no differences between the storers and nonstorers. This may have been due to the presence of spatial and nonspatial cues. It is also possible that storing and nonstoring tits perform similarly during matching-to-sample type procedures.

\section{Neural Substrates}

The central role of spatial memory in the recovery of scatter-hoarded food raises a number of questions about neural substrates. Which areas of the brain are used during cache recovery? What types of species differences in neural structure are associated with the evident differences between species in performance on cache recovery and other tests of spatial memory? In this section we review the literature relevant to these questions.

\section{I Role of the Hippocampus in Spatial Memory}

O'Keefe and Nadel (1978) first proposed a central role for mammalian hippocampus in spatial memory. This hypothesis has been confirmed by experiments in many different laboratory tasks (see Volume I, Chapter 33, and Volume II, Chapter 11, of Learning and Memory: A Comprehensive Reference (2008), ed. R. Menzel; ). Most of these experiments, however, have been carried out in mammals, while most research on spatial memory in scatter-hoarders has been carried out in birds. What is known about the avian hippocampus (Figure 6)?

In this context, it is interesting to note that there is a radically new view of brain evolution and the structure of the avian cerebrum, a view that emphasizes the large number of avian-mammalian homologies (Jarvis et al.,

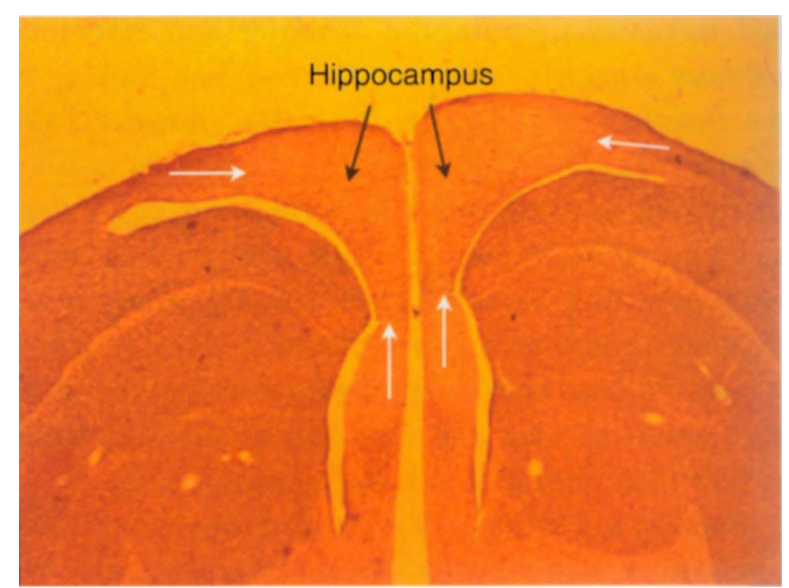

Figure 6. A photomicrograph of a coronal section through the avian hippocampus, with boundaries indicated by the white arrows. (Photograph by Kristy Gould.)

2005). This view has led to a proposal for a radical revision of the nomenclature for avian cerebrum, a nomenclature that "better reflects these functions and the homologies between avian and mammalian brains" (Jarvis et al., 2005: 2). Research with scatter-hoarding birds and mammals is consistent with this revision. The dorsomedial region of the avian telencephalon has been shown to be homologous to the mammalian hippocampal formation in many regards. This includes connectivity (Krayniak and Siegel, 1978; Casini et al, 1986; Szkeley and Krebs, 1996), distribution of neuropeptides and neurotransmitters (Erichsen et al., 1991; Krebs et al, 1991; Gould et al., 2001), generation of long-term potentiation (Shapiro and Wieraszko, 1996) and a theta rhythm (Siegel et al., 2000), electrophysiology (Siegel et al., 2002), and N-methyl-D-aspartate (NMDA) receptor activation (Shiflett et al., 2004) and immediate early gene expression (Smulders and DeVoogd, 2000b; Shimizu et al., 2004) during spatial tasks. Behaviorally, lesions to pigeon hippocampus disrupt performance on a variety of spatial memory tasks such as learning spatial representations in homing (reviewed in Bingman et al., 2005), spatial reversal learning (Good, 1987), spatial alternation (Reilly and Good, 1987), and spatial delayed matching-to-sample (Good and Macphail, 1994).

\subsection{The Hippocampus in Food-Storing Birds}

In the case of food-storing birds, hippocampal lesions disrupt cache retrieval. Krushinskaya (1966) lesioned the dorsomedial and dorsolateral sections of the hippocampus of Eurasian nutcrackers after they had stored 
food in a dirt-floored laboratory room. When given the opportunity to recover, lesioned birds retrieved 13\% of their caches while nonlesioned controls recovered around $90 \%$ of theirs. Although Krushinskaya's lesion methods were crude, and she may have inadvertently damaged areas outside of the hippocampus, later research has confirmed the role of hippocampus in cache recovery and spatial memory using lesion techniques on black-capped chickadees during both food storing (Sherry and Vaccarino, 1989) and delayed spatial matching-to-sample tasks (Hampton and Shettleworth, 1996). Temporary inactivation of the hippocampus in blackcapped chickadees also produces memory impairment in a spatial associative task (Shiflett et al., 2003), indicating hippocampal involvement in storing and retrieving spatial information in the short term.

These results strongly suggest that the species differences in spatial memory and cache recovery should be reflected in differences in hippocampal structure. Comparative studies of avian hippocampus have found that species that store food have a larger relative hippocampal size than those that do not (Krebs et al, 1989; Sherry et al., 1989; Garamszegi and Eens, 2004; Lucas et al., 2004; but see Brodin and Lundberg, 2003). Correlations are also found between food storing behavior, spatial memory performance, and relative hippocampal volume for foodstoring birds within corvids (Healy and Krebs, 1992; Basil et al., 1996) and parids (Hampton et al., 1995; Healy and Krebs, 1996), as well as in food-storing rodents within the kangaroo rat family (Jacobs and Spencer, 1994).

There are also population differences in hippocampal volume within species. Black-capped chickadees that live further north, in harsher climates (e.g., Alaska), store more food, perform better on spatial tasks, and have a larger hippocampus than birds living further south (e.g., Colorado) (Pravosudov and Clayton, 2002; but see Brodin et al., 1996). Similar population differences may exist in other species. For example, Pravosudov and de Kort (2006) analyzed the brains of a large number of scrub jays, which have been classified as storing fewer seeds (Balda and Kamil, 1989) and performing less accurately during many spatial memory tasks (e.g., Balda and Kamil, 1989; Olson, 1991, see previous); they have been found to have a smaller hippocampus than other food-storing corvids (Basil et al., 1996). Their data indicated a significantly larger relative hippocampal volume than the scrub jays in Basil et al. (1996). This difference in results may be due to methodological differences (paraffin-embedded vs. frozen tissue). On the other hand, the scrub jays used in the two studies came from different regions (northern Arizona and northern California), and there may be population differences within scrub jays in hippocampal size correlated with natural history.

\subsection{Experience, Seasonality, and Neurogenesis in Birds}

There are also important interactions between early environment, seasonality, and hippocampal growth. In at least some food-storing birds, early experience with food storing contributes to the development and ultimate size of adult hippocampus. When juvenile foodstoring parids are given the opportunity to store food, they perform better on tests of spatial memory (Clayton, 1995, 2001) and develop larger hippocampi with more neurons and an increased cell proliferation rate compared to food-storing parids that are not allowed to store food (Clayton, 1996; Patel et al., 1997). Juveniles given the opportunity to perform noncaching spatial memory tasks also perform better and have a larger hippocampus than those that were not (Clayton, 1995). The developing hippocampus seems to be sensitive to experience with tasks that require the recall of spatial locations, at least in food-storing parids. However, food-storing experience during adulthood does not change the volume or number of hippocampal neurons (Cristol, 1996). This all suggests that early experience with food storing leads to the development of a larger adult hippocampus with more neurons (Healy and Krebs, 1993, Healy et al., 1994) and a high cell proliferation rate (Patel et al., 1997).

Seasonal changes in the neural tissue associated with birdsong in species that sing seasonally are well known (Nottebohm, 1981). Similar phenomena have been demonstrated in birds that cache/recover seasonally. Barnea and Nottebohm (1994) studied hippocampal neurogenesis in adult black-capped chickadees and found a seasonal difference in neuronal recruitment, with more new neurons in October than any other time of year. This corresponds to a time of seasonal diet change, from insects to seeds, with many of the seeds being stored (see Pravosudov, 2006, for discussion of a bimodal peak in food storing among parids). Barnea and Nottebohm did not, however, find a seasonal difference in total number of hippocampal neurons. They hypothesized that seasonal recruitment is part of a neuronal replacement process important for the acquisition of new spa- 
tial memories. As seeds begin to be stored in October, new memories are established, requiring new neurons. Without a change in total neuron number, however, there must be apoptosis occurring as the new neurons are recruited.

Smulders et al. (1995) reported a seasonal change in the relative volume of the hippocampus in blackcapped chickadees, with the peak in October. This seemed to complement the results of Barnea and Nottebohm (1994). Smulders et al. (2000), however, concluded that this change in volume was related to an increase in the total number of neurons in the hippocampus. Barnea and Nottebohm did not find seasonal changes in total neuron number, only in the number of new neurons. Smulders and DeVoogd (2000a) hypothesized that the overall increase in neurons they found was the mechanism allowing greater processing of spatial information in the fall. The more neurons, the more spatial information can be processed. This differs from Barnea and Nottebohm's hypothesis of neuron replacement with no net gain in number of neurons.

Hoshooley and Sherry (2004) attempted to distinguish between the hypotheses of Barnea and Nottebohm (1994) and Smulders et al. (2000) by determining if the seasonal changes in chickadee hippocampus were a result of more 'new' neurons or an increase in the actual 'production' of neurons. They found no seasonal change in hippocampal volume, total neuron number, or neuron production, which suggests enhanced survival of new neurons in the fall, not an increase in neuron production. Smulders (2006), however, has pointed out that the birds used by Hoshooley and Sherry (2004) were held in captivity for up to 2 weeks before they were sacrificed and that captivity can cause decreases in neurogenesis (Barnea and Nottebohm, 1994) and hippocampal volume (Smulders and DeVoogd, 2000a) in birds.

There appear to be two mechanisms affecting hippocampal size in food-storing parids. First, food storing experience early in life increases adult hippocampal volume by influencing the total number of neurons and the extent of cell proliferation. Second, in adults, when demand for spatial memory increases because of foodstoring, either the number of hippocampal neurons increases or the number of new neurons that survive increases, resulting in a larger population of new hippocampal neurons to process new memories being formed. Further work will be necessary to fully understand the reasons for the increase in neuronal recruitment found by Barnea and Nottebohm (1994).
A possible complication is that cell proliferation is correlated with spatial memory and social status in mountain chickadees (Parus gambeli; Pravosudov and Omanska, 2005). Subordinate mountain chickadees performed worse on spatial memory tasks (Pravosudov et al., 2003) and also had lower cell proliferation rates (Pravosudov and Omanska, 2005) than their dominant counterparts. Individual birds that performed better on spatial memory tasks also had higher cell proliferation rates, suggesting a strong correlation between proliferation and spatial memory. However, no differences were found in hippocampal volume or total neuron number.

Other hippocampal differences have been found between food-storing and nonstoring birds. This includes larger calbindin-immunoreactive neurons in the hippocampus of food-storing than nonstoring corvids and parids (Montagnese et al., 1993) and significantly lower levels of NMDA-binding receptor sites in the hippocampus of food-storing parids (Stewart et al., 1999). How these differences might be related to food-storing is unclear. However, blocking NMDA receptors when blackcapped chickadees are learning a one-trial spatial association task prevents the retrieval of the food after either 3 or $24 \mathrm{~h}$. It also blocks learning about a new spatial location within the context of an already learned array of locations (Shiflett et al., 2004). This suggests that the avian hippocampus plays a role in linking new spatial locations into preexisting spatial memories (Smulders, 2006) and that NMDA receptor activation is important only in processing spatial information over the long term. Food-storing birds have fewer hippocampal NMDA receptor sites, which seems contradictory to these results. But this highlights the complexity of the relationship between the NMDA system and food-storing and the need for future work in this area.

\subsection{Role of the Hippocampus in Mammals}

In food-storing mammals, three studies have addressed species and seasonal differences in hippocampal neuroanatomy. Lavenex et al. $(2000 a, b)$ found no seasonal variations in hippocampal volume, total neuron number, or cell proliferation rates in the adult scatter-hoarding eastern gray squirrel (Sciurus carolinensis), an interesting contrast with the results from birds (Smulders et al. 1995, 2000) in terms of seasonal changes in volume and neuron number. Barker et al. (2005) compared the yellow pine chipmunk, both a lar- 
der- and scatter-hoarder, to the scatter-hoarding eastern gray squirrel during the fall when both species were actively collecting and storing food for winter. Gray squirrels had three times the number of proliferating cells in the dentate gyrus of the hippocampus, but no significant difference in the number of new neurons compared to the yellow pine chipmunk. There was a nonsignificant trend suggesting gray squirrels had more new neurons, and Barker et al. (2005) hypothesized that the greater number of proliferating cells provided a larger population from which to recruit new neurons into the hippocampus.

The Barker et al. (2005) results were quite different from those of Lavenex et al. (2000a) in terms of cell proliferation rates, but there were two major methodological differences. While Barker et al. used free-living animals sacrificed within $2 \mathrm{~h}$ of capture, Lavenex et al. used animals that had been in captivity for days before sacrificing. In addition, Barker et al. analyzed endogenous proteins that are indicators of neurogenesis, proteins that would be conserved at time of capture regardless of stress due to capture. Lavenex et al. assessed neurogenesis with a mitotic marker, which can be affected by stress of captivity (Barker et al., 2005). The results of Barker et al. (2005) were also different from those of Hoshooley and Sherry (2004), in that cell proliferation was related to spatial memory, but not the number of new neurons. These differences may also be the result of differences in stress due to captivity. It is also possible that there are different mechanisms producing hippocampal seasonal changes in mammals and birds.

\subsection{Other Brain Areas}

Brain areas other than the hippocampus play important roles in processing spatial information. However, the contribution of these areas to the recovery of scatter-hoarded food has not been investigated very thoroughly. These areas include the parahippocampal region (or Wulst in birds), the prefrontal cortex (or caudolateral nidopallium in birds), the septum, and visual areas. All of these brain regions have connections with the hippocampus in both mammals and birds and their contribution to spatial memory in mammals has been extensively studied. But we have little understanding of their contribution to spatial memory in birds or to scatter-hoarding in general for either rodents or birds. A handful of studies show general differences in the volume of two of these structures in food-storing birds. Gould et al. (2001) show that the medial substance P receptor field within the parahippocampal area of the food-storing black-capped chickadee is larger than that found in the nonstoring blue tit and great tit. Shiflett et al. (2002) showed that the septum is larger in chickadees than in blue and great tits. What these results mean in relation to food-storing is not clear, but research investigating brain regions connected with the hippocampus and their contributing role to spatial memory should be continued.

\subsection{Cognitive Pleiotropy}

Like genes, cognitive abilities can affect more than one trait. Spatial memory, for example, can facilitate territoriality or migration as well as cache recovery. This complicates the analysis of the relationship between natural history and cognition/neuroanatomy. If evolution has favored larger hippocampal volumes in some species, there must be strong advantages to such investment for those species, given the high cost of maintaining neural tissue (Attwell and Laughlin, 2001). But the hippocampus undoubtedly plays a significant role in behaviors other than relocating stored food. For example, Volman et al. (1997) looked at hippocampal volume in two species in each of two genera of woodpeckers. In Melanerpes, they found a larger hippocampus in a scatter-hoarding species than a larder-hoarder. But in Picoides, they found generally large hippocampal volumes even though neither Picoides species scatter-hoards. They suggest that factors other than scatter-hoarding may influence hippocampal size.

One such factor is migration. Healy et al. (1996) demonstrated that experience with migration has an impact on the size of the hippocampus in Garden warblers (Sylvia borin), who normally migrate from Europe to tropical Africa. They found that warblers at least 1 year old that have experience migrating have a larger hippocampus after at least one migration trip than 3month-old, naïve birds. In contrast, no age effect was found in nonmigratory Sardinian warblers (S. melanocephala momus), who had relatively small hippocampi, suggesting that it is the migratory experience and not some other maturational factor that affects hippocampus size.

Mettke-Hofmann and Gwinner (2003) extended these results with behavioral measures. They found better long-term spatial memory in migratory garden warblers 
than nonmigratory Sardinian warblers. Taken together, these studies suggest a picture for these migratory and nonmigratory congeners similar to that found for storing and nonstoring parids by Clayton and her colleagues (reviewed in section 3.2.2, "Memory for cache contents"). The connection between migration, spatial memory, and hippocampal structure is further indicated by the research of Cristol et al. (2003).

\section{Conclusions}

The study of spatial memory in scatter-hoarding animals has enriched the scientific understanding of animal cognition. The duration, capacity, and dynamism of this memory have driven impressive, stimulating research into both ultimate-evolutionary and proximateneurophysiological explanations. The most important impact of this research has probably been its contribution toward integrating biological and psychological approaches to animal cognition, combining concepts and designs from psychology with those from biology in a broadly evolutionary framework, leading to a better understanding of the complex relationships between natural history, cognition, and brain structure and function.

At another level, the cache recovery context has proved an extremely valuable setting for experiments on animal cognition. As our review has hopefully demonstrated, experiments on caching and recovery have extended ideas about the memorial capacities of animals. Many interesting questions about cache memory remain, questions such as the role of interference in forgetting, how information about the emptying of cache sites affects cache site memory, and exactly how cache site locations are encoded. In addition, caching and recovery are also providing an extremely useful context in which to study other important aspects of animal cognition such as episodic-like memory and social cognition (see Chapter 23 in Learning and Memory: A Comprehensive Reference, Volume I (2008), ed. R. Menzel).

\section{Acknowledgments}

Preparation of this manuscript was supported by NIMH grant MH61810.

\section{References}

Andersson M and Krebs J (1978) On the evolution of hoarding behaviour. Anim. Behav. 26: 707-7II.

Attwell D and Laughlin SB (200I) An energy budget for signaling in the grey matter of the brain. J. Cereb. Blood Flow Metab. 21:1133-1145.

Balda RP (1980) Recovery of cached seeds by a captive Nucifraga caryocatactes. Z.Tierpsychol. 52: 331-346.

Balda RP and Kamil AC (1989) A comparative study of cache recovery by three corvid species. Anim. Behav. 38: 486-495.

Balda RP and Kamil AC (1992) Long-term spatial memory in Clark's nutcracker. Anim. Behav. 44: 761-769.

Balda RP and Turek RJ (1984) The cache-recovery system as an example of memory capabilities in Clark's nutcrackers. In: Roitblat ML, Bever TG, and Terrace HS (eds.) Animal Cognition, Pp. 513532. Hillsdale, NJ: Lawrence Erlbaum Associates.

Balda RP, Kamil AC, and Grim K (1986) Revisits to emptied cache sites by Clark's nutcrackers (Nucifraga columbiana). Anim. Behav. 34: I289- 1298.

Balda RP, Pepperberg I, and Kamil AC (1998) Animal Cognition in Nature. New York:Academic Press.

Barker JM,Wojtowicz JM, and Boonstra R (2005) Where's my dinner? Adult neurogenesis in free-living food-storing rodents. Genes Brain Behav. 4:89-98.

Barkley CL and Jacobs LF (1998) Visual environment and delay affect cache retrieval accuracy in a food-storing rodent. Anim. Learn. Behav. 26: 439-447.

Barkley CL and Jacobs LF (2007) Sex and species differences in spatial memory in food-storing kangaroo rats. Anim. Behav. 73:321-329.

Barnea A and Nottebohm F (1994) Seasonal recruitment of hippocampal neurons in adult free-ranging black-capped chickadees. Proc. Natl.Acad. Sci. USA 91: | | 2 17- | | 221 .

Basil JA, Kamil AC, Balda RP, and Fite KV (1996) Differences in hippocampal volume among food storing corvids. Brain Behav. Evol. 47:156-164.

Bednekoff PA, Balda RP, Kamil AC, and Hile AG (1997a) Long-term spatial memory in four seed-caching corvid species. Anim. Behav. 53: 335-34l.

Bednekoff PA, Kamil AC, and Balda RP (1997b) Clark's nutcracker (Aves: Corvidae) spatial memory: Interference effects on cache recovery performance? Ethology 103: 554-565.

Bennett ATD (1993a) Remembering landmarks. Nature 364: 293-294.

Bennett ATD (1993b) Spatial memory in a food storing corvid. I. Near tall landmarks are primarily used. J. Comp. Physiol. A Sens. Neural Behav. Physiol. 173: 193-207.

Bingman VP, Gagliardo A, Hough GE, Paolo I, Kahn MC, and Siegel J (2005) The avian hippocampus, homing in pigeons and the memory representation of large-scale space. Integr. Comp. Biol. 45: 555-564.

Bossema I (1979) Jays and oaks: An eco-ethological study of a symbiosis. Behaviour 70: I-I I7.

Bossema I and Pot W (1974) Het terugvinden van verstopt voedsel door de Vlaamse gaai (Garrulus g. glandarius L). De Levende Natuur 77: 265-279.

Brodbeck DR (1994) Memory for spatial and local cues: A comparison of a storing and a nonstoring species. Anim. Learn. Behav. 22: II9-133. 
Brodbeck DR and Shettleworth SJ (1995) Matching location and color of a compound stimulus: Comparison of a food-storing and a nonstoring bird species. J. Exp. Psychol. Anim. Behav. Process. 21: 64-77.

Brodin A (2005) Mechanisms of cache retrieval in long-term hoarding birds. J. Ethol. 23: 77-83.

Brodin A and Kunz C (1997) An experimental study of cache recovery by hoarding willow tits after different retention intervals. Behaviour 134: 881-890.

Brodin A and Lundborg K (2003) Is hippocampal volume affected by specialization for food hoarding in birds? Proc. R. Soc. Lond. B Biol. Sci. 270: I555-I 563.

Brodin A, Lahti K, Lens L, and Suhonen J (1996) A northern population of willow tits Parus montanus did not store more food than southern ones. Ornis Fennica 73: I I4- I I8.

Casini G, Bingman VP, and Bagnoli P (1986) Connections of the pigeon dorsomedial forebrain studies with WGA-HRP and $3 \mathrm{H}$ proline. J. Comp. Neurol. 245: 454-470.

Cheng K and Sherry DF (1992) Landmark-based spatial memory in birds (Parus atricapillus and Columba livia): The use of edges and distances to represent spatial positions. J. Comp. Psychol. 106: $33|-34|$.

Clayton NS (1995) Development of memory and the hippocampus: Comparison of food-storing birds on a one-trial associative memory task. J. Neurosci. 15: 2796-2807.

Clayton NS (1996) Development of food-storing and the hippocampus in juvenile marsh tits. Behav. Brain Res. 74: I53-159.

Clayton NS (200I) Hippocampal growth and maintenance depend on food-caching experience in juvenile mountain chickadees (Poecile gambeli). Behav. Neurosci. I I5: 614-625.

Clayton NS and Dickinson A (1999) Memory for the content of caches by scrub jays (Aphelocoma coerulescens). J. Exp. Psychol. Anim. Behav. Process. 25: 82-91.

Clayton NS and Krebs JR (1994) One-trial associative memory: Comparison of food-storing and nonstoring species of birds. Anim. Learn. Behav. 22: 366-372.

Cowie RJ, Krebs JR, and Sherry DF (198I) Food storing by marsh tits. Anim. Behav. 29: I252-1259.

Cristol D (1996) Food storing does not affect hippocampal volume in experienced adult willow tits. Behav. Brain Res. 81:233-236.

Cristol DA, Reynolds EB, LeClerc JE, Donner AH, Farabaugh CS, and Ziegenfus CWS (2003) Migratory dark-eyed juncos, Junco hyemalis), have better spatial memory and denser hippocampal neurons than nonmigratory conspecifics. Anim. Behav. 66:317-328.

Crystal JD and Shettleworth SJ (1994) Spatial list learning in blackcapped chickadees. Anim. Learn. Behav. 22: 77-83.

Erichsen JT, Bingman VP, and Krebs JR (I99I) The distribution of neuropeptides in the dorsomedial telencephalon of the pigeon $\left(\mathrm{Co}_{0}\right.$ lumba livia): A basis for regional subdivisions. J. Comp. Neurol. 3।4: 478-492.

Gallistel CR (1990) The Organization of Learning. Cambridge, MA: MIT Press.

Garamszegi LZ and Eens M (2004) The evolution of hippocampus volume and brain size in relation to food hoarding in birds. Ecol. Lett. 7: 1216-1224.

Gibb J (1960) Populations of tits and goldcrests and their food supply in pine plantations. Ibis 102: 163-208.

Good M (1987) The effects of hippocampal-area parahippocampalis lesions on discrimination learning in the pigeon. Behav. Brain Res. 26: |7|-184.
Good M and Macphail EM (1994) The avian hippocampus and shortterm memory for spatial and non-spatial information. Q. J. Exp. Psychol. 47B: 293-317.

Goodyear AJ and Kamil AC (2004) Clark's nutcrackers (Nucifraga columbiana) and the effects of goal-landmark distance on overshadowing. J. Comp. Psychol. I I8: 258-264.

Gould KL, Newman SW, Tricomi EM, and DeVoogd TJ (200I) The distribution of substance $P$ and neuropeptide $Y$ in four songbird species: A comparison of food-storing and non-storing birds. Brain Res. 918: 80-95.

Gould-Beierle KL (2000) A comparison of four corvid species in a working and reference memory task using a radial maze. J. Comp. Psychol. I 14: 347-356.

Gould-Beierle KL and Kamil AC (1996) The use of local and global cues by Clark's nutcrackers Nucifraga columbiana. Anim. Behav. 52: 519-528.

Gould-Beierle KL and Kamil AC (1998) Use of landmarks in three species of food-storing corvids. Ethology 104: 36I-378.

Gould-Beierle KL and Kamil AC (1999) The effect of proximity on landmark use in Clark's nutcrackers. Anim. Behav. 58: 477-488.

Haftorn S (1954) Contribution to the food biology of tits especially about storing of surplus food. Part I. The crested tit (Parus c. cristatus L). Det Kgl Norske Videnskabers Selskabs Skrifter $1953 \mathrm{Nr}$ 4: I-I 23.

Hampton RR and Shettleworth SJ (1996) Hippocampal lesions impair memory for location but not color in passerine birds. Behav. Neurosci. I 10:831-835.

Hampton RR, Sherry DF, Shettleworth SJ, Khurgel M, and Ivy G (1995) Hippocampal volume and food-storing behavior are related in parids. Brain Behav. Evol. 45: 54-6I.

Healy SD (1995) Memory for objects and positions: Delayed-nonmatching-to-sample in storing and non-storing tits. Q. J. Exp. Psychol. 48B: I79-19|.

Healy SD and Krebs JR (1992) Food storing and the hippocampus in corvids:Amount and volume are correlated. Proc. R. Soc. Lond. B Biol. Sci. 248: 24I-245.

Healy SD and Krebs JR (1993) Development of hippocampal specialisation in a food-storing bird. Behav. Brain Res. 53: |27-I3I.

Healy SD and Krebs JR (1996) Food storing and the hippocampus in Paridae. Brain Behav. Evol. 47: 195- 199.

Healy SD and Suhonen J (1996) Memory for locations of stored food in willow tits and marsh tits. Behaviour 133: 7I-80.

Healy SD, Clayton NS, and Krebs JR (1994) Development of hippocampal specialisation in two species of tit (Parus spp.). Behav. Brain Res. 61: 23-28.

Healy SD, Gwinner E, and Krebs JR (1996) Hippocampal volume in migratory and non-migratory warblers: Effects of age and experience. Behav. Brain Res. 8I: 6I-68.

Herz RS, Zanette L, and Sherry DF (1994) Spatial cues for cache retrieval by black-capped chickadees. Anim. Behav. 48: 343-35I.

Hilton SC and Krebs JK (1990) Spatial memory of four species of Parus: Performance in an open-field analogue of a radial maze. Q. J. Exp. Psychol. 42B: 345-368.

Hitchcock CL and Sherry DF (1990) Long-term memory for cache sites in the black-capped chickadee.Anim. Behav. 40:70I-7I 2.

Hoshooley JS and Sherry DF (2004) Neuron production, neuron number, and structure size are seasonally stable in the hippocampus of the food-storing black-capped chickadee (Poecile atricapillus). Behav. Neurosci. I I 8: 345-355. 
Jacobs LF (1992) Memory for cache locations in Merriam's kangaroo rats. Anim. Behav. 43: 585-593.

Jacobs LF and Liman ER (199I) Grey squirrels remember the locations of buried nuts. Anim. Behav. 4I: 103-II0.

Jacobs LF and Shiflett MW (1999) Spatial orientation on a vertical maze in free-ranging fox squirrels (Sciurus niger). J. Comp. Psychol. I|3:116-127.

Jacobs LF and Spencer WD (1994) Natural space-use patterns and hippocampal size in kangaroo rats. Brain Behav. Evol. 44:125-132.

Jarvis E, Gunturkun O, Bruce L, et al. (2005) Avian brains and a new understanding of vertebrate brain evolution. Nature Rev. Neurosci. $6: 15 \mid-159$.

Jones JE and Kamil AC (200I) The use of relative and absolute bearings by Clark's nutcrackers Nucifraga columbiana. Anim. Learn. Behav. 29: I20-132.

Jones JE, Antoniadis E, Shettleworth SJ, and Kamil AC (2002) A comparative study of geometric rule learning by nutcrackers (Nucifraga columbiana), pigeons (Columba livia), and jackdaws (Corvus monedula). J. Comp. Psychol. I I6: 350-356.

Kamil AC and Balda RP (1985) Cache recovery and spatial memory in Clark's nutcrackers Nucifraga columbiana. J. Exp. Psychol. Anim. Behav. Process. II: 95- III.

Kamil AC and Balda RP (1990) Differential memory for cache sites in Clark's nutcrackers Nucifraga columbiana. J. Exp. Psychol. Anim. Behav. Process. 16: 162-168.

Kamil AC and Cheng K (200I) Way-finding and landmarks:The multiple-bearings hypothesis. J. Exp. Biol. 204:103-I I3.

Kamil AC and Jones JE (1997) The seed-caching corvid Clark's nutcracker learns geometric relationships among landmarks. Nature 390:276-279.

Kamil AC and Jones JE (2000) Geometric rule learning by Clark's nutcrackers (Nucifraga columbiana). J. Exp. Psychol. Anim. Behav. Process. 26: 439-453.

Kamil AC, Balda RP, Olson DJ, and Good S (1993) Revisits to emptied cache sites by Clark's nutcrackers (Nucifraga columbiana): A puzzle revisited.Anim. Behav. 45: 24I-252.

Kamil AC, Balda RP, and Olson DJ (1994) Performance of four seedcaching corvid species in the radial-arm maze analog. J. Comp. Psychol. 108: 385-393.

Kamil AC, Balda RP, and Good S (1999) Patterns of movement and orientation during caching and recovery by Clark's nutcrackers Nucifraga columbiana. Anim. Behav. 57: I327-I 335.

Kamil AC, Goodyear AJ, and Cheng K (200I) The use of landmarks by Clark's nutcrackers: First tests of a new model. J. Navigation 54: 429-435.

Krayniak PF and Siegel A (1978) Efferent connections of the hippocampus and adjacent regions in the pigeon. Brain Behav. Evol. I5:372-388.

Krebs JR, Healy SD, and Shettleworth SJ (1990) Spatial memory of Paridae: Comparison of a storing and a non-storing species, the coal tit Parus ater, and the great tit P. major. Anim. Behav. 39: I I27- I I37.

Krebs JR, Sherry DF, Healy SD, Perry VH, and Vaccarino AL (I989) Hippocampal specialization of food-storing birds. Proc. Natl. Acad. Sci. USA 86: 1388-1392.

Krebs JR, Erichsen JT, and Bingman VP (199I) The distribution of neurotransmitters and neurotransmitter-related enzymes in the dorsomedial telencephalon of the pigeon (Columba livia). J. Comp. Neurol. 314: 467-477.

Krushinskaya NL (1966) Some complex forms of feeding behavior of nutcrackers Nucifraga caryocatactes, after removal of their old cortex. J. Evol. Biochem. Physiol. I I: 564-568.

Lavenex P, Shiflett MW, Lee RK, and Jacobs LF (1998) Spatial versus nonspatial relational learning in free-ranging fox squirrels (Sciurus niger). J. Comp. Psychol. I I2: I27-136.

Lavenex P, Steele MA, and Jacobs LF (2000a) The seasonal pattern of cell proliferation and neuron number in the dentate gyrus of wild adult eastern grey squirrels. Eur. J. Neurosci. 12:643-648.

Lavenex P, Steele MA, and Jacobs LF (2000b) Sex differences, but no seasonal variations in the hippocampus of food-caching squirrels: A stereological study. J. Comp. Neurol. 425:I52-I66.

Lewis JL and Kamil AC (2006) Interference effects in the memory for serially presented locations in Clark's nutcrackers. J. Exp. Psychol. Anim. Behav. Process. 32: 407-4I8.

Lucas JR, Brodin A, DeKort SR, and Clayton NS (2004) Does hippocampal size correlate with the degree of caching specialization? Proc. R. Soc. Lond. B Biol. Sci. 27I: 2433-2429.

MacDonald DW (1976) Food-caching by red foxes and some other carnivores. Z. Tierpsychol. 42: 170-185.

Macdonald IMV (1997) Field experiments on duration and precision of grey and red squirrel spatial memory. Anim. Behav. 54: 879-891.

Mettke-Hofmann C and Gwinner E (2003) Long-term memory for a life on the move. Proc. Natl.Acad. Sci. USA I00(10): 5863-5866.

Moller A, Pavlick B, Hile AG, and Balda RP (200I) Clark's nutcrackers Nucifraga columbiana remember the size of their cached seeds. Ethology 107: 45I-46I.

Montagnese CM, Krebs JR, Szekely AD, and Csillag A (1993) A subpopulation of large calbindin-like immunopositive neurones is present in the hippocampal formation in food-storing but not in non-storing species of bird. Brain Res. 6I4: 29|-300.

Nottebohm F (198I) A brain for all seasons: Cyclical anatomical changes in song control nuclei of the canary brain. Science 2। $4: 1368-1370$.

O'Keefe J and Nadel L (1978) The Hippocampus as a Cognitive Map. Oxford: Clarendon Press.

Olson D (1989) Comparative Spatial Memory in Birds. PhD Thesis, University of Massachusetts Amherst.

Olson DJ (1991) Species differences in spatial memory among Clark's nutcrackers, scrub-jays, and pigeons. J. Exp. Psychol. Anim. Behav. Process. 17: 363-376.

Olson DJ, Kamil AC, Balda RP, and Nims PJ (1995) Performance of four seed-caching corvid species in operant tests of nonspatial and spatial memory. J. Comp. Psychol. 109:173-181.

Patel SN, Clayton NS, and Krebs JR (1997) Spatial learning induces neurogenesis in the avian brain. Behav. Brain Res. 89:I15-I28.

PravosudovW (2006) On seasonality in food-storing behaviour in parids: Do we know the whole story? Anim. Behav. 7I: | 455- I460.

Pravosudov W and Clayton NS (2002) A test of the adaptive specialization hypothesis: Population differences in caching, memory, and the hippocampus in black-capped chickadees (Poecile atricapilla). Behav. Neurosci. I 16:5 I5-522.

Pravosudov W and de Kort SR (2006) Is the western scrub-jay (Aphelocoma californica) really an underdog among food-caching corvids when it comes to hippocampal volume and food caching propensity? Brain Behav. Evol. 67: I-9.

Pravosudov W and Omanska A (2005) Dominance-related changes in spatial memory are associated with changes in hippocampal cell proliferation rats in mountain chickadees. J. Neurobiol. $62: 3|-4|$ 
Pravosudov W, Mendoza SP, and Clayton NS (2003) The relationship between dominance, corticosterone, memory, and food caching in mountain chickadees. Horm. Behav. 44: 93-102.

Reilly S and Good M (1987) Enhanced DRL and impaired forcedchoice alternation performance following hippocampal lesions in the pigeon. Behav. Brain Res. 26:185-197.

Shapiro E and Wieraszko A (1996) Comparative, in vitro, studies of hippocampal tissue from homing and non-homing pigeon. Brain Res. 725:199-206.

Sherry DF (1982) Food storage, memory and marsh tits. Anim. Behav. 30:631-633.

Sherry DF (1984) Food storage by black-capped chickadees: Memory for the location and contents of caches. Anim. Behav. 32: $45 \mathrm{I}-464$.

Sherry DF and Vaccarino AL (1989) Hippocampus and memory for food caches in black-capped chickadees. Behav. Neurosci. 103:308-318.

Sherry DF, Krebs JR, and Cowie RJ (198I) Memory for the location of stored food in marsh tits. Anim. Behav. 29: 1260-1266.

Sherry DF, Vaccarino AL, Buckenham K, and Herz RS (1989) The hippocampal complex of food-storing birds. Brain Behav. Evol. 34:308-3I7.

Shettleworth SJ (1998) Cognition Evolution and Behavior. Oxford: Oxford University Press.

Shettleworth SJ and Krebs JR (1982) How marsh tits find their hoards: The roles of site preference and spatial memory. J. Exp. Psychol. Anim. Behav. Process. 8: 354-375.

Shettleworth SJ, Krebs JR, Healy SD, and Thomas CM (1990) Spatial memory of food-storing tits (Parus ater and P. atricapillus): Comparison of storing and nonstoring tasks. J. Comp. Psychol. 104: $7 \mid-8 I$.

Shiflett MW, Gould KL, Smulders TV, and DeVoogd TJ (2002) Septum volume and food-storing behavior are related in Parids. J. Neurobiol. 5l: 215-222.

Shiflett MW, Smulders TV, Benedict L, and DeVoogd TJ (2003) Reversible inactivation of the hippocampal formation in food-storing black-capped chickadees (Poecile atricapillus). Hippocampus 13:437-444.

Shiflett MWT, Tomaszycki ML, Rankin AZ, and DeVoogd TJ (2004) Long-term memory for spatial locations in a food-storing bird (Poecile atricapilla) requires activation of NMDA receptors in the hippocampal formation during learning. Behav. Neurosci. II8: I2I-I30.

Shimizu R, Bowers AN, Budzynski CA, Kahn MC, and Bingman VP (2004) What does a pigeon (Columba livia) brain look like during homing? Selective examination of ZENK expression. Behav. Neurosci. I I8: 845-85।.

Siegel JJ, Nitz D, and Bingman VP (2000) Hippocampal theta rhythm in awake, freely moving homing pigeons. Hippocampus I0:627-23I.

Siegel JJ, Nitz D, and Bingman VP (2002) Electrophysiological profile of avian hippocampal unit activity: $A$ basis for regional subdivisions. J. Comp. Neurol. 445: 256-268.

Smulders TV (2006) A multi-disciplinary approach to understanding hippocampal function in food-hoarding birds. Rev. Neurosci. 17: 53-69.

Smulders TV and DeVoogd TJ (2000a) The avian hippocampal formation and memory for hoarded food: Spatial learning out in the real world. In: Bolhuis J (ed.) Brain Perception Memory.Advances in Cognitive Neuroscience, pp. 127-I48. Oxford: Oxford University Press.
Smulders TV and DeVoogd TJ (2000b) Expression of immediate early genes in the hippocampal formation of the black-capped chickadee (Poecile atricapillus) during a food-hoarding task. Behav. Brain Res. II 4: 39-49.

Smulders TV, Sasson AD, and Devoogd TJ (1995) Seasonal variation in hippocampal volume in a food-storing bird, the black-capped chickadee. J. Neurobiol. 27: I5-25.

Smulders TV, Shiflett MW, Sperling AJ, and DeVoogd TJ (2000) Seasonal changes in neuron numbers in the hippocampal formation of a food-hoarding bird: The black-capped chickadee. J. Neurobiol. 44: 4I4-422.

Spetch ML, Rust TB, Kamil AC, and Jones JE (2003) Searching by rules: Pigeons' (Columba livia) landmark-based search according to constant bearing or constant distance. J. Comp. Psychol. II7: I23-132.

Stewart MG, Cristol D, Philips R, et al. (1999) A quantitative autoradiographic comparison of binding to glutamate receptor subtypes in hippocampus and forebrain regions of a food-storing and a non-food-storing bird. Behav. Brain Res. 98:89-94.

Szekely AD and Krebs JR (1996) Efferent connectivity of the hippocampal formation of the zebra finch (Taenopygia guttata): An anterograde pathway tracing study using Phaseolus vulgaris leucoagglutinin. J. Comp. Neurol. 368: 198-2। 4.

Tomback DF (1980) How nutcrackers find their seed stores. Condor 82:10-19.

Vander Wall SB (1982) An experimental analysis of cache recovery in Clark's nutcracker. Anim. Behav. 30: 84-94.

Vander Wall SB (1990) Food Hoarding in Animals. Chicago: University of Chicago Press.

VanderWall SB (1991) Mechanisms of cache recovery by yellow pine chipmunks. Anim. Behav. 4I:85I-863.

Vander Wall SB (2000) The influence of environmental conditions on cache recovery and cache pilferage by yellow pine chipmunks (Tamias amoenus) and deer mice (Peromyscus maniculatus). Behav. Ecol. I I: 544-549.

Volman SF, Grubb TC, and Schuett KC (1997) Relative hippocam$\mathrm{pal}$ volume in relation to food-storing behavior in four species of woodpeckers. Brain Behav. Evol. 49: I I0-I 20.

Watanabe S (2005) Strategies of spatial learning for food storing in scrub jays. J. Ethol. 23: I8I-I87.

Wiltschko W and Balda RP (1989) Sun compass orientation in seedcaching scrub jays. J. Comp. Physiol.A 164: 717-72I.

Wiltschko W, Balda RP, Jahnel M, and Wiltschko R (1999) Sun compass orientation in seed-caching corvids: Its role in spatial memory. Anim. Cogn. 2: 215-221.

Wright AA (2006) Memory processing. In: Wasserman EA and Zentall TR (eds.) Comparative Cognition: Experimental Explorations of Animal Intelligence, pp. I64-185. New York: Oxford University Press.

Wright AA, Santiago HC, Sands SF, and Urcuioli PJ (1984) Pigeon and monkey serial probe recognition: Acquisition, strategies, and serial position effects. In: Roitblat HL, Bever TG, and Terrace HS (eds.) Animal Cognition, pp. 353-374. Hillsdale, NJ: Erlbaum Associates. 